\title{
National interests and coalition positions on climate change: A text-based analysis
}

Paula Castro (paula.castro@zhaw.ch)

ORCID: 0000-0002-5818-301X

University of Zurich and Zurich University of Applied Sciences, Switzerland

This is the post-print version of Castro, P. (2020). National interests and coalition positions on climate change: A text-based analysis. International Political Science Review, DOI: 10.1177/0192512120953530.

\begin{abstract}
Coalitions play a central role in the international negotiations under the United Nations Framework Convention of Climate Change. By getting together, countries join resources in defending their interests and positions. But building coalitions may come at a cost: Coalition positions are a result of compromise between their members, and thus the increase in bargaining power might come at a price if the preferences of its members are heterogeneous. Relying on automatic text analysis of written position papers submitted to the negotiations, I analyze the extent to which coalitions represent the preferences of their members and discuss whether this contributes to disproportionate policy responses at the international level. I focus on a recently formed coalition: the Like-Minded Developing Countries, a large and heterogeneous group that brings together emerging, oil-dependent and poor developing countries.
\end{abstract}

\section{Keywords}

UNFCCC, Domestic politics, Coalitions, International negotiations, Text analysis, Two-level game 


\section{Introduction}

International negotiations are well-known as a two-level bargaining game between the domestic stakeholders that influence a country's international position, and the international level in which this country defends its position, typically while negotiating with other countries with potentially different domestic interests (Putnam, 1988). However, particularly in multilateral negotiations, there is a third bargaining level that has been so far hardly understood as such: country coalitions.

Coalitions, defined as sets 'of parties who coordinate explicitly among themselves and defend the same position' (Odell, 2013: 386), play a central role in multilateral negotiations by fulfilling two main goals. First, they reduce complexity by lowering the number of relevant actors and by highlighting common interests and positions. Second, they increase their members' negotiating power and influence by allowing them to pool resources and expertise and to show strength in numbers (Dupont, 1996).

However, coalition positions are themselves a result of compromise between their members. In the words of Starkey et al. (2005: 40), coalition formation leads to a 'negotiation within a negotiation'. Coalitions can thus be regarded as a third level to be added to Putnam's well-known model. The increase in bargaining power that coalitions offer might come at a price for individual members, because joining a coalition may mean accepting a more restrictive set of alternative negotiation outcomes that can be acceptable to all coalition partners. This risk is larger for coalitions whose members have heterogeneous preferences, or for coalitions with tighter rules.

Despite the very relevant role that coalitions play in multilateral negotiations, most scholarship on coalitions focuses on describing the aggregate positions adopted by these groups, their strategies, and their success in influencing multilateral negotiations. But very little research has looked into how coalitions work as an intermediate bargaining level between the domestic interests of parties and the multilateral arena.

In this article, I draw on the public policy literature on disproportionate policy responses to shed light on this aspect of coalitions. Disproportionate policy responses as those with a lack of fit between their costs and benefits or their means and ends, implying policy over- or under-reactions (Maor et al., 2017). This literature has discussed whether disproportionate policy responses are unintentional results of differing risk preferences of policymakers, cognitive biases, misperceptions or disproportionate information (Maor, 2014), or rather the result of strategic political calculations that, depending on the circumstances, emphasize policy effectiveness over its costs or risks, or vice versa (Maor et al., 2017; Maor, 2018).

In line with past research on coalitions in multilateral negotiations, I argue that when a coalition brings together an heterogeneous group of countries, the differences in preferences will make it difficult to achieve common positions, and that those common positions will likely be dominated by the powerful in the group (Narlikar, 2003: 16; Narlikar and Tussie, 2004). The result will likely be coalition positions that fail to adequately represent all the preferences of some of the weaker members. For these weaker members, then, 
the position adopted by the coalition amounts to policy under-reaction and 'provides net utility (...) which is smaller than the one that would have been obtained had a different' position been adopted (Maor et al., 2017: 599).

Climate policy may be particularly prone to policy over- and under-reactions due to the psychological and socio-cultural factors influencing perceptions of climate change, to the uncertainty about climate change impacts (Tosun et al., 2017), and to the large range of stakeholders that may be strongly affected by climate change and climate policy. These disproportionate policy responses are carried over to the international level, namely in the form of international agreements that have so far not been sufficient to achieve the overall objective of maintaining climate change below dangerous levels (Maor et al., 2017). The United Nations Environment Programme's emissions gap report (UNEP, 2019) provides a clear indication of the level of climate policy underreaction currently existing globally. The argument in this article suggests that heterogeneous coalitions may help to transmit those disproportionate policy responses from the domestic to the international level.

This article thus aims at improving our knowledge about the connections between domestic climate politics and the international level, by analyzing the extent to which coalitions are able to represent the priorities and preferences of their members, and discussing whether this contributes to disproportionate policy responses at the international level. It is conceived as a complementary piece to Tosun and Rinscheid (this issue), who explore the ways in which domestic and international factors affect countries' decisions to participate in international initiatives on climate change.

I use the example of a recently created coalition active in the climate change negotiations under the United Nations Framework Convention on Climate Change (UNFCCC). The Like-Minded Developing Countries (LMDC) is a large coalition that brings together an heterogeneous group of countries from across the world, including large emerging economies such as China and India, oil-dependent countries such as Saudi Arabia, Iran or Kuwait, and vulnerable and poor developing countries such as Bolivia, Cuba or Sudan, all with different interests and priorities regarding climate change.

The focus on this coalition is driven by several considerations. First, its heterogeneous membership makes it an ideal candidate to analyze whether and how countries manage to reconcile their diverging priorities under a single umbrella. In addition, both the LMDC as a group and many of its members have been quite active in the negotiations, which offers sufficient empirical evidence to assess their negotiation positions.

Second, LMDC is a relatively new, still under-studied coalition, created in 2012 right after the negotiations towards the 2015 Paris Agreement started. This is a crucial period in the climate negotiations, that witnessed a paradigmatic shift in international climate politics, from a system of top-down emission reduction commitments for a small group of developed countries under the Kyoto Protocol, to one of self-determined mitigation contributions for all country parties under the Paris Agreement, in which the traditional 
differentiation between Annex I (developed) countries and non-Annex I (developing) countries was substantially eroded. In addition, the fact that these negotiations covered many issues, ranging from mitigation to adaptation, support for developing countries, transparency of action, among others, enables me to disentangle the issue areas for which the coalition forms (or does not form) common positions and to discuss the reasons behind.

Third, LMDC emerged as a result of the growing fragmentation of the main developing country coalition in the climate negotiations: the Group of 77 and China (G77). While the $G 77$ has always been a very heterogeneous group, the climate-relevant differences in emissions and income levels between its members have grown strongly over time (Kasa et al., 2007; Vihma et al., 2011). This increasing heterogeneity, along with the ever-expanding negotiation agenda, has resulted in the emergence of several new and overlapping coalitions of developing countries (Roberts, 2011; Castro and Klöck, in press). Among these new groupings, LMDC portrays itself as being closely aligned with G77 and as a defender of developing countries' interests in the UNFCCC. One of its main aims is to uphold the regime's traditional differentiation between developed and developing countries, in line with the historical responsibility of developed countries for greenhouse gas emissions and with the equity implications deriving from it (Blaxekjær and Nielsen, 2015). It is thus substantively interesting to see whether the traditional G77 positions continue to be heralded by LMDC along the pre- and post-Paris era.

Recent research has sought to identify the positions and narratives adopted by coalitions in the climate negotiations. Blaxekjær, Nielsen and colleagues (2015; in press) applied narrative policy analysis to study the positions of several new country coalitions under the UNFCCC, including LMDC. Audet (2013) uses qualitative discourse analysis to map the positions of nine coalitions on climate justice. Cluster analysis on the negotiation issues raised by developing countries' statements (Woods and Kristófersson, 2016), their economic, geographic, energy-related and other characteristics (Costantini et al., 2016), and their type of climate pledges (Tobin et al., 2018) has been used to propose ideal coalitions and compare them to the existing ones. While these are very valuable contributions, they fail to discuss how differences in domestic preferences and power are played out in establishing a coalition position. Researching coalition decisionmaking is challenging, as it resembles a black box, where documentary evidence on their internal planning is not publicly available, and interviewees may not want to speak openly on it either.

In this article, I apply novel content analysis tools to assess whether and to what extent a coalition represents the issues that its members care about. I rely on a corpus of 222 written position statements submitted to the UNFCCC by LMDC and its members in the period 2013-2018. I begin by briefly outlining how negotiation positions form at the domestic and the coalition level, before proposing a set of hypotheses on how coalition characteristics might influence the extent to which they are able to effectively represent their members' domestic preferences at multilateral negotiations. I then describe the empirical setting and present the original data and the novel content analysis tool applied. Finally, I present and discuss the results, and draw conclusions about the role of coalitions as a middle level that may amplify disproportionate policy 
responses in the complex interplay between domestic preferences and international positions on climate change.

The article offers several important contributions. First, it adds to the theory regarding the role of coalitions in multilateral negotiation settings, by looking at the interlinkages between coalition positions and national interests of coalition members. It thereby describes a so-far missing link in the chain between domesticlevel politics and international bargaining processes. Second, it contributes to the literature on disproportionate policy responses, by discussing how these are transferred from the domestic to the international level. Third, it presents part of a new, comprehensive corpus of written position papers submitted to the UNFCCC negotiations. Finally, it also demonstrates the use of structural topic models as a useful tool to identify the issues that are relevant to individual stakeholders in a complex multilateral, multiissue negotiation such as climate change.

\section{Countries' positioning in the climate change negotiations}

Countries' positioning in multilateral negotiations is driven both by their domestic interests or preferences and by the negotiation setting. Countries pursue some particular international outcome that is within their win-set - the potential outcomes that are likely to be accepted by the relevant domestic stakeholders (Putnam, 1988). To achieve this outcome they follow a particular negotiating strategy. Their negotiation positions are never a clean revelation of their preferred outcome, as they might also reflect strategies such as exaggerating positions to gain a bargaining advantage, or lobbying for a second-best outcome if the preferred one is unattainable. Beyond domestic preferences, in this article I focus on how coalition formation affects positions in the climate change negotiations. ${ }^{1}$

\section{Domestic preferences}

Countries' positions in the negotiations are partly a function of their individual climate policy preferences, which in turn result from a negotiation across the different relevant stakeholders and interest groups in the country (Putnam, 1988). Simplifying from this two-level game, but still applying a rational choice lens, recent research has related these aggregated preferences to three main underlying variables (Roberts, 2011). First, countries' climate-related preferences depend on their level of responsibility for climate change (their greenhouse gas emissions), and the ease or difficulty they would have in reducing these emissions. For example, economies that are strongly dependent on fossil fuels or on high-emissions industries are opposed to strong mitigation measures. Domestically, countries with a strong fossil fuel lobby will be characterized by climate policy under-reaction (Maor et al., 2017), while internationally they will seek to obstruct a strong deal, while emphasizing the adverse effect of climate policies on their economies (Depledge, 2008). Second, countries' preferences depend on their capability to address those emissions, understood as countries' income and related financial, institutional and technological capacity (see, e.g. Upadhyaya et al., this issue), but also their political ability to adopt and effectively implement climate policies. And third, countries' 
preferences depend on their vulnerability to the impacts of climate change. For instance, given their high vulnerability, the small island developing states have stood out for proposing strong mitigation policies, lobbying for support for adaptation to the impacts of climate change, and introducing the concept of compensation for losses and damages already experienced.

\section{Role of coalitions}

Coalitions emerge out of the need of countries to engage more effectively in negotiations and make their voices heard. Some level of common interest is a necessary condition for coalition formation and maintenance. Shared values, a common ideology or a sense of group identity have been posited as other factors that may help coalitions to remain together (Roberts, 2011; Bhandary, 2017).

Nonetheless, Tobin et al. (2018) have found that members of the same coalition are not necessarily similar in terms of the mitigation policies that they adopt. This suggests that, sometimes, coalition partners might not share the same climate-related interests. Indeed, coalitions are sometimes built on the basis of geographic location (i.e. regional groups such as the African Group) or other non-climate-related common characteristics (such as development status for the Least Developed Countries). While members of such groups might share some climate-related concerns, they may have substantial differences regarding others.

In the case of diverging domestic preferences, coalition positions are the result of compromise between their members. Thus, if the preferences of the individual members of a coalition are very heterogeneous, the increase in bargaining power gained by joining a coalition may come at a price, particularly for the weakest members of the coalition which are less likely to make their preferences prevail.

Coalitions are particularly important for smaller and poorer states with low negotiating capacity (Panke, 2012), particularly in a setting in which discussions on different agenda issues run in parallel, and where substantial technical expertise is required (Atela et al., 2017). While larger and more powerful countries are generally less willing to act through coalitions (Allan and Dauvergne, 2013), they may be driven to use coalition-building as a tool for convincing other countries to support their own interests (Narlikar, 2003).

What does this mean for the way in which coalitions represent their member states' positions and priorities? First, because countries join coalitions in order to gain strength in numbers, they will expect the coalitions to represent their views and preferences. Doing so offers several advantages: more visibility, because the coalition represents many individual voices ; more expertise, because working through the coalition provides access to experts from other members; and the support and understanding from the coalition partners. But this strategy might not always work, particularly when coalitions are heterogeneous and their members have diverging interests and power resources. In these cases, we would expect the coalition to be able to represent views on issues that are uncontroversial for its members (where there is substantial agreement across all members, or where members might not have sufficient expertise, so that they rely on the group (or its leaders) for advice), and in addition, as explained above, to preferably represent the preferences of its 
strongest members. Coalition members that don't see their preferences being sufficiently represented by the group might in this case opt to communicate these preferences individually or in other groups of likelyminded countries.

On the basis of the above discussion, I derive the following hypotheses:

H1: Heterogeneous coalitions are not able to represent the national preferences of all of their members to the same extent.

H2: Heterogeneous coalitions more strongly reflect the national preferences of their strongest members than those of the weaker ones.

H3: Individual countries whose national preferences are not sufficiently represented by their coalition will try to make those preferences be heard by participating in the negotiations individually or in smaller groups.

It needs to be noted that the relationship between individual country and coalition positions is not a unidirectional one. ${ }^{2}$ Generally, countries tend to join partners and coalitions that have views similar to their own, as this makes it easier to gain trust in each other and to reach common positions. This means that it is very difficult to disentangle the extent to which coalitions represent the views of their members from the extent to which countries join coalitions with which they already agreed in the first place.

This reverse causality, however, makes the test of our hypotheses a more difficult one: If we assume that countries join coalitions with which they already agree, then we would not be surprised if those coalitions represent the same positions as the individual members. We are however more interested in the opposite case: when coalitions fail to appropriately represent the views of some of their members (H1), in how this is related to the distribution of power among these members $(\mathrm{H} 2)$, and what this implies for individual members' negotiation behavior (H3).

\section{The case: LMDC in the climate negotiations}

LMDC emerged in 2012, right after the UNFCCC parties decided to start negotiations towards a new agreement to deal with climate change after 2020, in which all countries would be expected to contribute to mitigation. This new process became known as the ADP - the Ad Hoc Working Group on the Durban Platform for Enhanced Action, which in 2015 concluded with the adoption of the Paris Agreement.

\section{The negotiation setting}

The emergence of the coalition is related to a crucial period in the climate change negotiations that arguably started in 2007 with the Bali Action Plan. This plan was the first indication that the climate change regime was slowly progressing from the strong differentiation between developed and developing countries established under the Kyoto Protocol, towards a system with more meaningful participation of developing 
countries in mitigation. The Bali Action Plan introduced the notion of voluntary mitigation actions by developing countries, which were subject to financial support. Despite the failure in Copenhagen (2009) to reach a new comprehensive climate agreement for the period after 2012, the Cancun Agreements of 2010 enshrined this bottom-up approach with voluntary mitigation pledges, also for developing countries. The 2015 Paris Agreement became the culmination of this regime transformation process by relying on the notion of Nationally Determined Contributions by all parties: a bottom-up system in which each party is free to determine the extent of its contribution to addressing climate change. The countries most likely to face costs as a result of the institutional change towards universal participation tried strongly to prevent it from becoming a system where all parties would contribute in a comparable ('uniform') manner to mitigation. Particularly developing countries with high greenhouse gas emissions levels knew that they would be expected to contribute meaningfully to mitigation, so that they lobbied for continued international underreaction to the climate problem by demanding the maintenance of the old annex-based differentiation.

The agreement was also supposed to not only address emission reductions, but also adaptation to the impacts of climate change, financial and technological support for developing countries, capacity building and transparency, inter alia (UNFCCC Decision 1/CP.17). This offered the opportunity for countries with strong domestic interests on some of these issues to propose their preferred policies in these areas as well. In addition, some parties also lobbied for other issues - such as compensation for loss and damage - to be included in the agenda and the agreement.

\section{LMDC: The Like-Minded Developing Countries}

LMDC held its first official meeting in October 2012. This group heralds itself as being closely aligned with the G77 and representing the key interests of developing countries. Accordingly, one of its key positions recognized in the literature is that the differentiation between developed and developing countries' contributions to mitigation should remain (Blaxekjær and Nielsen, 2015).

LMDC is a rather large and very heterogeneous group, whose membership is not fully transparent and seems to be fluid. Only seven LMDC written submissions from the years 2012-2014 list the countries that belong to the group. Later submissions simply refer to LMDC without detailing who the coalition represents. However, many written submissions are delivered by one particular member on behalf of the group, which offers further evidence of who are the most engaged members. Finally, the summaries of the UNFCCC negotiations published by the International Institute for Sustainable Development in its Earth Negotiations Bulletins (ENBs) also usually record who speaks on behalf of the group. Based on these three sources of data on coalition membership, Figure 1 displays all countries that have ever been mentioned as being part of or representing LMDC, ranking them according to frequency of such mentions. This results in a list of 20 core members, which have actively represented the coalition at least once. In addition, I identify eight peripheral members which have been listed as members of LMDC at least once, but have never been recorded as actively representing LMDC. In comparison, Blaxekjær et al. (in press) identify up 
to 41 different countries as potential LMDC members, with a core group of 13 countries that are mentioned regularly, while Hirsch (2016:2) refers to a 'hard core of around 15 members, with another 10 to 15 countries sometimes participating. ${ }^{3}$ These differing views highlight the (likely strategic) opaqueness of the group in terms of its membership, which allows it to strengthen its identity as 'the true representative of the G77' (Blaxekjær et al., in press).

[Figure 1 here]

LMDC brings together several key members of the G77. This core group includes China and India, the two largest greenhouse gas emitters among the developing countries, along with oil-dependent economies such as Saudi Arabia, Iran, Algeria and Venezuela (also Iraq, Qatar and Kuwait participate often in LMDC submissions). While China has embraced clean energy as a win-win solution for addressing climate change, strengthening its industrial base and tackling local air pollution (Tosun and Rinscheid, this issue), India's widespread poverty and low per capita emissions have led her to consistently reject responsibility for climate change mitigation (Jaeger and Michaelowa, 2016). The oil-dependent economies, quite strongly represented in LMDC with 9 OPEC members participating in the coalition, have the most to lose from a strong climate agreement. Led by Saudi Arabia, they have typically strived to slow down the negotiation process and have historically argued for addressing the impacts that climate policies (response measures) would have on their economies (Depledge, 2008). Interestingly, several poorer and vulnerable developing countries, including Bolivia, Cuba, Dominica, El Salvador, Mali, Sri Lanka and Sudan are part of LMDC. Several of these smaller LMDC members also belong to ALBA (the Bolivarian Alliance for the Peoples of Our America), a group of left-oriented Latin American countries that started to engage with the climate negotiations in 2009 and holds ideologically-driven positions that reject neoliberalism and capitalism, while emphasizing equity, the historical responsibility of developed countries and their resulting climate debt (Watts and Depledge, 2018). Two LMDC members have publicly left the group. In December 2014, the Philippines announced during COP 20 that it would accept heading the Climate Vulnerable Forum, a group consisting of vulnerable climate-progressive countries, which supports more ambitious climate action. Similarly, Argentina left LMDC in December 2015 to start coordinating positions with Brazil and Uruguay, forming the new ABU (Argentina-Brazil-Uruguay) coalition. In both cases, the move was at least partly motivated due to changes in domestic politics with respect to climate change. While the Philippines, as a vulnerable country, decided that it was not in its interest to side with China and the oil producers (Fontanilla, 2014), Argentina's new government decided to project a more progressive international position in line with its center-right views (Bueno, 2018).

Oil-dependent economies have sufficient financial resources and a strong motivation to use the coalition in order to further their goal of preventing strong international climate policies. In addition, China and India are two pivotal countries for the climate regime, given their large size, emerging economies and high share of global emissions. I therefore expect that particularly these countries will be successful in using the LMDC to project their domestic preferences towards the international level. 


\section{Data and methods}

Data

The analysis is based on a new corpus of 222 written position statements (or 'submissions') sent to the UNFCCC negotiations by LMDC, as well as its individual member countries and subgroups of members in the period 2013-2018. I include statements that were made by LMDC as a group together with other countries or coalitions, but exclude statements made by individual member countries together with nonmember countries. The corpus includes all English-language, machine-readable submissions made to six UNFCCC negotiation bodies active in the relevant time period. All documents were downloaded from the UNFCCC website. A few position statements were submitted by the same country with exactly the same wording twice. I exclude these duplicate submissions as they do not offer additional information.

Submissions are usually sent in response to calls for views on the current items in the negotiation agenda. The agenda items covered by the submissions are therefore not random, but follow the progress of the discussions. However, while some calls for submissions are very specific in their scope (e.g. requests for submissions on 'Further guidance in relation to the adaptation communication'), others are quite broad (e.g. submissions on 'Information, views and proposals on the work of the ADP'). Figure B3 in the Supplementary File cross-tabulates the topics identified in the corpus with the issue areas covered by the UNFCCC agenda items, hand-coded from the calls for submissions.

Table A1 and Figures A1-A3 in the Supplementary File provide further details on the documents contained in the corpus.

\section{Descriptive analysis of submissions corpus}

I start with a descriptive analysis of the numbers of documents submitted by LMDC and its members to reach first conclusions about how the LMDC represents the priorities of its members in the UNFCCC negotiations.

Since LMDC is an heterogeneous coalition, I expect it is not able to fully represent the views of all of its members, so that some of them will be driven to submit position statements of their own. Therefore, I expect the corpus to include both submissions by the coalition as a whole, and submissions by individual (or subgroups of) members (Betzold et al., 2012; Watts and Depledge, 2018).

In addition, I expect LMDC to more strongly represent the views of its stronger members (H2), so that its weaker members will try to communicate their preferences through individual submissions (H3). I therefore expect there to be comparatively more individual submissions by weaker members than by stronger ones. However, weaker countries might on average be less capable of producing written submissions, given their 
resource limitations. I therefore focus on weak LMDC members that were already active in making written submissions before the coalition was created.

Conceptualizing power in the climate negotiations is not straightforward. The conventional measure of power in IR, military might, does not play a role in these discussions. Instead, income might be a better measure as it reflects countries' ability to hire and maintain specialized personnel. Additionally, the size of a country's population, economy or emissions are good indicators of its global relevance for mitigating climate change. Also countries that are particularly vulnerable to climate change frequently display more clout than would be expected given their size and resources, driven by the power of the moral arguments they can draw from (Betzold, 2010). Finally, countries might gain bargaining power by maintaining personnel within their negotiation delegations with deep and long-term knowledge of the issues at stake. For an exploratory study such as this it is not possible to consider all of these elements. I therefore rely mainly on country size and income to discuss the role of power.

\section{Structural topic models}

I apply a structural topic model (STM) to identify the topics or issues that are addressed in the texts. The STM is an unsupervised machine learning method that allows to identify topics within texts by iteratively estimating the distribution of words within topics and of topics within texts (Roberts et al., 2014b, 2016). In contrast to traditional topic models, structural topic models use additional information about the texts (i.e. characteristics of their authors, time of writing, and other document-level covariates) to improve the estimation process (Roberts et al., 2016). In comparative politics, STMs have been applied, for example, to estimate how China's rise has been covered by different newswire services (Roberts et al., 2016). In environmental politics, they have been used to study what topics citizens relate to climate change in surveys (Tvinnereim and Fløttum, 2015). The STM allows me to disentangle the issues - including, but not limited to the agenda items under discussion - that appear in LMDC members' submissions. It further allows me to assess how prevalent those different issues are within the submissions made by individual countries or by the coalition itself.

Before the STM was estimated, the submission texts were cleaned and pre-processed with the help of the package quanteda in R (Benoit et al., 2018) This pre-processing is described in the Supplementary File. I use three document-level covariates for estimating the STM. To account for the fact that different countries prioritize different topics in the negotiations, I add a dummy identifying the country (or subgroup) producing each submission. As the topics and language of the negotiations might evolve non-linearly over time, I include a spline of the year of submission. Finally, different issues are typically discussed under different negotiation bodies of the UNFCCC. I thus include a dummy for the negotiation body to which each submission was sent (Table A1 in the Supplementary File). 
The most crucial step in estimating topic models is the selection of the number of topics. There is no golden rule for the number of topics that can be found in a specific corpus, as it simply changes the level of granularity in classifying the textual data. An appropriate value depends on the type of corpus and the goal of the analysis. In this article, I am looking for clearly identifiable issue-areas that allow me to differentiate the policy priorities of different country parties. I thus need a number of topics that is large enough to find differences across countries, but small enough to be clearly identifiable. I estimate 22 topic models using the stm package in $R$ (Roberts et al., 2014a), varying the number of topics between 15 and 40 . I use a combination of statistical measures of fit and qualitative assessment of the most-probable and mostexclusive words characterizing each topic to reach a decision on the optimal number of topics. I assess both the semantic coherence (i.e. how frequently the most probable words in a given topic co-occur together) and exclusivity (how neatly the words discriminate between the different topics) of the models and topics therein. After careful assessment of the models, I choose the one with 30 topics for the analysis. Most of the topics identified are stable when looking at models with 19 to 37 topics, which is an indication of a good model. In addition, the model with 30 topics allowed me to clearly label the topics, while offering a level of detail that goes beyond simple UNFCCC agenda items to reveal some of the more specific preferences of the countries. Appendix B in the Supplementary File presents the 30 topics identified by the STM and discusses the model's overall good performance in pinpointing the most relevant issues being discussed in the climate negotiations, as well as their evolution over time.

After identifying the topics, I use topic prevalence (the share of words attributable to each topic in a document) to identify the issues that LMDC and its members focus on in their submissions. On this basis, I discuss the ways in which countries use individual and coalition submissions to represent their domestic preferences on the issue areas they care about in the negotiations.

\section{Results}

\section{Individual versus coalition submissions}

Table 1 summarizes the number of written submissions made by LMDC, its members and subgroups of members. LMDC has been quite active in producing written submissions since it was created (70 documents). At the same time, individual members or subgroups of members of LMDC produce a sizable number of submissions (152). This may suggest that some of them might feel compelled to individually voice views that are not being sufficiently represented by the group.

Table 2 offers a more detailed view of the submissions produced by individual members of LMDC in the period 2013-2018. It shows that stronger members of the coalition are. on average, more active than weaker ones in producing position statements, against my expectation under hypothesis 2 . It should be noted that several of the comparatively weaker members of LMDC were quite active in the negotiations before LMDC was established, with for example Sri Lanka producing 36 submissions in the period 2007-2012, Argentina 
22, Pakistan 21, Ecuador 15, the Philippines 14 and Egypt 10. Therefore, while these countries clearly have the capacity to actively participate through written submissions in the negotiations, they now mostly seem to rely on the coalition to represent their views. The four exceptions are Algeria, Bolivia, Malaysia and Thailand, which keep similar levels of individual submissions after joining LMDC. So far, thus, there is no support for the hypothesis the more heterogeneous coalitions tend to better reflect the national preferences of their strongest members.

[Tables 1 and 2 approximately here]

How does $L M D C$ represent the views of its members in its submissions: Topic prevalence

Figure 2 compares the prevalence of topics across LMDC actors. For each topic, the graph ranks those countries or groups (including LMDC) for which the topic's prevalence across all submissions adds up to at least 1. Figures B1 and B2 in the Supplementary File more generally rank the topics in terms of their average prevalence and their prevalence over time.

The topics reflect the issues that were under discussion in the Paris Agreement negotiations, but also offer information about more specific priorities of LMDC and its members within each issue area, about LMDC's more general negotiation positions. Some of them reflect typical negotiation language. A first group of topics addresses issues related to climate vulnerability, impacts and agriculture (topics 1-4), a second group covers finance and support (topics 5-9). Topics 10 to 12 reflect some cross-cutting issues that developing countries and LMDC members in particular care deeply about, including the Convention principles of Common but Differentiated Responsibilities and Respective Capabilities (CBDR-RC) and of equity; poverty eradication, poverty and related adverse effect from climate change; and the impacts of response measures. Topics 13 to 16 cover reporting, review and compliance, while discussions on NDC guidance, the global stocktake and pre-2020 ambition are covered in topics 17 to 20. Discussions related to market and nonmarket mechanisms and REDD (reducing emissions from deforestation and forest degradation) are covered in topics 21 to 24 . A set of topics (25-28) captures typical negotiation language, such as the openings of submissions or the modalities of discussion. The final two topics address mitigation technologies and policies, and gender.

The Supplementary File presents a more detailed description of all topics and what they cover, and ranks them in terms of their prevalence (Figure B1). Amongst the most prevalent topics are some central issues in the post-Paris negotiations, including guidance for NDCs, the transparency framework and the transparency communications. Support is the most prevalent topic overall, reflecting a key demand of developing countries, and the fact that LMDC frequently highlights developed countries' obligation to provide such support. Similarly, the model is accurate in identifying the principles of the Convention as one of the most prevalent topics, which is in line with the narratives most strongly defended by the group (Blaxekjær et al., in press). 
[Figure 2 about here]

As a general pattern, Figure 2 shows that LMDC as a coalition engages extensively with a large set of negotiation topics. For most of the topics, it is the LMDC itself which appears on top of the ranking as the actor with the highest prevalence. This is of course related to the fact that the LMDC is the actor that has delivered the most submissions during the period of study. LMDC as a coalition has been particularly active on topics related to the implementation of the Paris Agreement (topics 14-19), but also on topics related to finance and support, the Convention principles, reporting, review and compliance, and market and nonmarket mechanisms. Typically, also China and India tend provide extensive inputs on these topics. More generally, individual LMDC members not only prepare submissions on topics in which LMDC tends to be rather quiet (such as agriculture, response measures, vulnerability, REDD and gender), but they also prepare submissions on topics in which LMDC is active as a group. In the first case, this suggests that the coalition has not reached a common position and therefore individual members with a stake on those issues express their views individually, supporting hypothesis 3 . In the second, two explanations are possible. Either those individual member submissions express similar positions to those of the coalition as a whole, which would suggest a coordinated strategy to enhance the visibility of those positions, or they diverge from the views of LMDC, which would support my argument about insufficient representation of (the weaker) members of the coalition (hypotheses 1 and 2).

Looking in more detail at individual LMDC members we notice that weaker countries mostly focus on topics including vulnerability, agriculture, some aspects of support, non-market mechanisms, REDD and gender. Both weak and strong members offer views on reporting of support, response measures, markets and LULUCF, while mostly strong members focus on finance for own projects, the Convention principles, and the more technical aspects of reporting, review and compliance, as well as NDC guidance and the global stocktake. It seems that topics such as adaptation to climate change, financial support, and emissions from forest degradation, which concern many poor developing countries, are not sufficiently addressed by LMDC. Therefore, weaker members of the coalition see the need to offer their own views on these issues. This finding supports hypothesis 3.

I turn to the submissions on two of the topics most prevalent among weaker LMDC members to gain more insight on their actual positions and whether these converge or diverge: vulnerability (topic 2) and REDD (topic 24). Vulnerability is covered mostly by the submissions under the agenda item of adaptation. REDD is addressed under the agenda items on REDD and on market and non-market mechanisms (Figure B3 in the Supplementary Files).

14 submissions were made under the agenda item on adaptation. Reading through these submissions suggests a division of labor between LMDC and its members, rather than inadequate representation or divergent views. LMDC and some of its most powerful members (China, India, Kuwait) deliver ideas on the central topic under negotiation (in this case the adaptation communications), which are quite supportive 
of each other. Smaller members (Sri Lanka, Thailand, Malaysia), in contrast. mainly produce submissions under other ongoing processes, such as the Nairobi Work Programme on Adaptation or the National Adaptation Plans, which they use to highlight their own vulnerabilities, adaptation initiatives and/or adaptation planning processes. These are complementary, rather than divergent positions and priorities.

12 submissions were made on REDD; all of them by individual LMDC members. The five Bolivian texts propose and describe the Joint Mitigation and Adaptation Mechanism (JMAM), a non-market-based policy approach to dealing with deforestation and forest degradation as an alternative to REDD. Submissions by China and the Philippines express support for non-market approaches for REDD without being as detailed as the Bolivian ones. Other members, like Ecuador, fail to mention market or non-market approaches for REDD or the JMAM. In contrast, Malaysia offers some qualified support for the JMAM, but highlights that REDD should be considered primarily a mitigation action, and that non-carbon benefits should not be a pre-requisite for REDD activities. This is contrary to Bolivia's view of JMAM as a holistic instrument with significant non-carbon benefits. These submissions suggest that LMDC members' views on REDD and the JMAM are not fully aligned, which explains the lack of a common coalition position on this topic and the large number of individual submissions. These findings therefore support hypotheses 1 and 3. Moreover, they support the idea that the failure of the coalition members to converge on a common position around specific issues that are important to some of its (weaker) members, such as the JMAM, leads to a form of policy under-reaction, characterized by a lack of a common submission on the issue, and a multiplicity of submissions with partly divergent views.

\section{Conclusions}

This article offers theoretical contributions to the literatures on the role of coalitions in multilateral negotiations and on disproportionate policy responses, as well as empirical contributions in terms of a new corpus of written position papers submitted to UNFCCC negotiations and of demonstrating the use of structural topic models to identify negotiation issues within those position papers.

At the theory level, I propose that coalitions form an understudied third level in multilateral negotiation processes, situated in the middle between the national-level politics of finding a domestic consensus on how to address climate change, and the international-level process of reaching a global agreement on this issue. Bringing together international relations literature on the role of coalitions in multilateral negotiations and public policy literature on disproportionate policy responses, I analyze the extent to which coalitions are able to represent the priorities and preferences of their members, and discuss whether this contributes to disproportionate policy responses at the international level.

I propose that coalitions with heterogeneous members will have a difficult time in reaching common positions that represent the national preferences of all of their members. Rather, their common positions will most likely reflect the interests and preferences of the powerful members of the group and fail to 
adequately represent the potentially more ambitious or more encompassing preferences of some of the weaker members. This amounts to policy under-reaction from the point of view of those weaker members, who are then obliged to present their views individually.

Using structural topic models in order to map the issues that LMDC, a relatively large and heterogeneous developing country coalition active in the climate negotiations, and its members care about, I find that member countries use a combination of individual and coalition submissions to present their views in the negotiations. Against my expectations, LMDC seems to be able to speak with a unified voice on a large range of topics, including those at the heart of the Paris negotiations. There are some topics, however, where LMDC as a coalition is relatively (or even completely) quiet, while weaker members of the coalition are particularly active. In these cases, this suggests that LMDC is not fully able to represent the climate policy preferences of all its members. This seems to be particularly the case for issues that are important for its smaller and weaker members, such as adaptation and vulnerability, addressing deforestation, or gender issues. Looking in more detail at the submissions on adaptation and deforestation reveals two types of coalition strategies. In the first case, there seems to be a division of labor between the coalition - which focuses on the most central agenda items such as adaptation communications - and its individual members - who contribute with information about their own vulnerabilities and initiatives to address them. In addition, the most powerful coalition members - particularly China and India - seem to play an important role in further emphasizing the coalition's message in their own submissions. In the case of deforestation, LMDC has failed to find a common position, so that Bolivia is relatively alone in its quest for proposing a Joint Mitigation and Adaptation Mechanism, with some support by individual LMDC partners, and rather contradictory views by others. Joining large and powerful countries may have been useful for Bolivia - and the other ALBA countries - in terms of gaining strength, expertise and visibility, but it may not be so effective in helping them to achieve some of their negotiation aims.

In summary, despite it being quite an heterogeneous coalition, LMDC has so far been able to put together common positions on a wide range of important issues in the climate negotiations. For those topics that are relevant to a smaller subset of its members, particularly the weaker ones, however, it cannot perform a similar representational role, so that individual countries voice their views individually. This supports the three central hypotheses of this article. As coalitions systematically give more weight to the positions and preferences of their strongest members, in a way, this process thus helps to transfer instances of policy under-reaction from the domestic to the international level.

\section{Acknowledgements}

I would like to thank Jale Tosun and Guy Peters, as well as the editors of International Political Science Review and three anonymous referees for their thoughtful and constructive comments and suggestions, which helped me to improve the manuscript substantially. 


\section{Funding statement}

Financial support by the Swiss National Science Foundation (Grant No. PMPDP1_171273) is gratefully acknowledged.

\section{Notes}

${ }^{1}$ This focus does not detract from the fact that other aspects of the negotiation setting, such as institutional characteristics or the role of other stakeholders (other countries and coalitions, transnational corporations and NGOs, IGOs, etc.) may also affect positions.

2 I thank an anonymous referee for pointing this out.

3 According to Blaxekjær et al. (in press), the countries that have at least once subscribed to a written submission by LMDC are: Algeria, Argentina, Bahrain, Bolivia, China, Comoros, Democratic Republic of Congo, Cuba, Djibouti, Dominica, Ecuador, Egypt, El Salvador, Ghana, India, Iran, Iraq, Jordan, Kuwait, Lebanon, Libya, Malaysia, Maldives, Mali, Mauritania, Morocco, Nicaragua, Oman, Pakistan, Paraguay, Philippines, Qatar, Saudi Arabia, Somalia, Sri Lanka, Sudan, Syria, Thailand, Tunisia, Venezuela, Yemen (italics indicate those countries that appear in all LMDC submissions listing its members). The difference between this country list and the one shown on Figure 1 is due to the fact that Blaxekjær et al. also count submissions made in 2012 by a group of countries with a similar membership than LMDC, which however did not (yet) call itself LMDC. 


\section{References}

Allan, Jen I and Peter Dauvergne (2013) The Global South in Environmental Negotiations: The politics of coalitions in REDD+. Third World Quarterly 34(8): 1307-1322.

Atela, Joanes O, Claire H Quinn, Albert A Arhin, Lalisa Duguma and Kennedy L Mbeva (2017) Exploring the Agency of Africa in Climate Change Negotiations: The case of REDD+. International Environmental Agreements: Politics, Law and Economics 17(4): 473-482.

Audet, René (2013) Climate Justice and Bargaining Coalitions: A discourse analysis. International Environmental Agreements: Politics, Law and Economics 13(3): 369-386.

Benoit, Kenneth, Kohei Watanabe, Haiyan Wang, Paul Nulty, Adam Obeng, Stefan Müller and Akitaka Matsuo (2018) quanteda: An R package for the quantitative analysis of textual data. Journal of Open Source Software 3(30): 774 .

Betzold, Carola (2010) 'Borrowing' Power to Influence International Negotiations: AOSIS in the climate change regime, 1990-1997. Politics 30(3): 131-148.

Betzold, Carola, Paula Castro and Florian Weiler (2012) AOSIS in the UNFCCC Negotiations: From unity to fragmentation? Climate Policy 12(5): 591-613.

Bhandary, Rishikesh Ram (2017) Coalition Strategies in the Climate Negotiations: An analysis of mountainrelated coalitions. International Environmental Agreements: Politics, Law and Economics 17(2): 173-190.

Blaxekjær, Lau Øfjord and Tobias Dan Nielsen (2015) Mapping the Narrative Positions of New Political Groups under the UNFCCC. Climate Policy 15(6): 751-766.

Blaxekjær, Lau Øfjord, Bård Lahn, Tobias Dan Nielsen, Lucia Green-Weiskel and Fang Fang (in press) The Narrative Position of the Like-Minded Developing Countries in Global Climate Negotiations. In Carola Klöck, Paula Castro, Florian Weiler and Lau Øfjord Blaxekjær (eds) Coalitions in the Climate Change Negotiations. London: Routledge.

Bueno, María del Pilar (2018) Cambio, Identidades e Intereses: Argentina en las negociaciones multilaterales de cambio climático 2015-2017. Colombia Internacional 96: 115-145.

Castro, Paula and Carola Klöck (in press) Fragmentation in the Climate Change Negotiations: Taking stock of the evolving coalition dynamics. In Carola Klöck, Paula Castro, Florian Weiler and Lau Øfjord Blaxekjær (eds) Coalitions in the Climate Change Negotiations. London: Routledge.

Costantini, Valeria, Giorgia Sforna and Mariangela Zoli (2016) Interpreting Bargaining Strategies of 
Developing Countries in Climate Negotiations. A quantitative approach. Ecological Economics 121:128-139.

Depledge, Joanna (2008) Striving for No: Saudi Arabia in the climate change regime. Global Environmental Politics 8(4): 9-35.

Dupont, Christophe (1996) Negotiation as Coalition Building. International Negotiation 1(1): 47-64.

Fontanilla, Denise M (2014) The Philippines - from Like-Minded to Climate Vulnerable, GMA News Online, 10 December. https://www.gmanetwork.com/news/scitech/science/391994/the-philippinesfrom-like-minded-to-climate-vulnerable/story/.

Hirsch, Thomas (2016) The Role of Alliances in International Climate Policy after Paris. Berlin: FriedrichEbert-Stiftung. https://eulacfoundation.org/en/system/files/the role_of alliance.pdf

Jaeger, Mark D and Katharina Michaelowa (2016) Global Climate Policy and Local Energy Politics: Is India hiding behind the poor? Climate Policy 16(7): 940-951.

Kasa, Sjur, Anne T Gullberg and Gørild Heggelund (2007) The Group of 77 in the International Climate Negotiations: Recent developments and future directions. International Environmental Agreements: Politics, Law and Economics 8(2): 113-127.

Maor, Moshe (2014) Policy Persistence, Risk Estimation and Policy Underreaction. Policy Sciences 47: 425443.

Maor, Moshe (2018) Rhetoric and Doctrines of Policy Over- and Underreactions in Times of Crisis. Policy \& Politics 46(1): 47-63.

Maor, Moshe, Jale Tosun and Andrew Jordan (2017) Proportionate and Disproportionate Policy Responses to Climate Change: Core concepts and empirical applications. Journal of Environmental Policy \& Planning 19(6): $599-611$.

Narlikar, Amrita (2003) International Trade and Developing Countries: Bargaining Coalitions in the GATT and WTO. London \& New York: Routledge.

Narlikar, Amrita and Diana Tussie (2004) The G20 at the Cancun Ministerial: Developing countries and their evolving coalitions in the WTO. World Economy 27(7): 947-966.

Odell, John S (2013) Negotiation and Bargaining. In Walter Carlsnaes, Thomas Risse, and Beth A Simmons (eds) Handbook of International Relations, 2nd Edition. London: Sage. 
Panke, Diana (2012) Dwarfs in International Negotiations: How small states make their voices heard. Cambridge Review of International Affairs 25(3): 313-328.

Putnam, Robert D (1988) Diplomacy and Domestic Politics: The logic of two-level games. International Organization 42(3): 427-460.

Roberts, J Timmons (2011) Multipolarity and The New World (Dis)order: US hegemonic decline and the fragmentation of the global climate regime. Global Environmental Change 21(3): 776-784.

Roberts, Margaret E, Brandon M Stewart and Dustin Tingley (2014a) stm: R package for structural topic models.

Roberts, Margaret E, Brandon M Stewart, Dustin Tingley, Christopher Lucas, Jetson Leder-Luis, Shana K Gadarian, Bethany Albertson and David G Rand (2014b) Structural Topic Models for Open-ended Survey Responses. American Journal of Political Science 58: 1064-1082.

Roberts, Margaret E, Brandon M Stewart and Edoardo M Airoldi (2016) A Model of Text for Experimentation in the Social Sciences. Journal of the American Statistical Association 111(515): 988-1003.

Starkey, Brigid, Mark A Boyer and Jonathan Wilkenfeld (2005) Negotiating a Complex World: An Introduction to International Negotiation. Lanham, MD: Rowman \& Littlefield.

Tobin, Paul, Nicole M Schmidt, Jale Tosun and Charlotte Burns (2018) Mapping States' Paris Climate Pledges: Analysing targets and groups at COP 21. Global Environmental Change 48: 11-21.

Tosun, Jale, Andrew Jordan and Moshe Maor (2017) Governing Climate Change: The (dis)proportionality of policy responses. Journal of Environmental Policy \& Planning 19(6): 596-598.

Tosun, Jale and Adrian Rinscheid (n.d.) Joining the Clean Energy Ministerial: An integrated analysis of the domestic and international factors. Paper submitted to this Special Issue.

Tvinnereim, Endre and Kjersti Fløttum (2015) Explaining Topic Prevalence in Answers to Open-ended Survey Questions about Climate Change. Nature Climate Change 5(8): 744-747.

UNEP (2019) Emissions Gap Report 2019. Nairobi: UNEP.

Upadhyaya, Prabhat, Manish Kumar Shrivastava, Ganesh Gorti and Saliem Fakir (n.d.) "Effective" Implementation of NDCs - Institutional capacity in India and South Africa. Paper submitted to this Special Issue. 
Vihma, Atto, Yacob Mulugetta and Sylvia Karlsson-Vinkhuyzen (2011) Negotiating Solidarity? The G77 through the prism of climate change negotiations. Global Change, Peace \& Security 23(3): 315-334.

Watts, Joshua and Joanna Depledge (2018) Latin America in the Climate Change Negotiations: Exploring the AILAC and ALBA coalitions. WIREs Climate Change 9(6): 1-14.

Woods, Bryndís A and Daði M Kristófersson (2016) The State of Coalitions in International Climate Change Negotiations and Implications for Global Climate Policy. International Journal of Environmental Policy and Decision Making 2(1): 41-68.

\section{Author biography}

Paula Castro is research associate at the Center for Energy and Environment of the Zurich University of Applied Sciences, and was previously at the Department of Political Science of the University of Zurich, Switzerland. Her work analyses the role of institutions and bargaining strategies in international environmental negotiations, and the adoption and effectiveness of policy instruments for climate change mitigation. 
Table 1: Number of individual vs. coalition submissions

\begin{tabular}{lc}
\hline Number of submissions by: & $2013-2018$ \\
\hline Full coalition & 68 \\
Individual members & 151 \\
Subgroups of members & 1 \\
Coalition with others & 2 \\
\hline
\end{tabular}


Table 2: Submissions by individual LMDC members, 2013-2018

\begin{tabular}{|c|c|}
\hline Country & $\begin{array}{c}\text { Number of submissions } \\
(2013-2018)\end{array}$ \\
\hline \multicolumn{2}{|l|}{ Weak members: } \\
\hline Algeria & 8 \\
\hline Argentina & 1 \\
\hline Bolivia & 19 \\
\hline Cuba & 1 \\
\hline Congo. Dem. Rep. & 5 \\
\hline Ecuador & 5 \\
\hline Egypt & 2 \\
\hline Iran & 1 \\
\hline Jordan & 1 \\
\hline Malaysia & 8 \\
\hline Nicaragua & 1 \\
\hline Pakistan & 6 \\
\hline Philippines & 2 \\
\hline Sri Lanka & 5 \\
\hline Sudan & 2 \\
\hline Thailand & 5 \\
\hline Venezuela & 1 \\
\hline \multicolumn{2}{|c|}{ Strong members / subgroups: } \\
\hline ALBA & 1 \\
\hline China & 32 \\
\hline India & 27 \\
\hline Kuwait & 6 \\
\hline Saudi Arabia & 13 \\
\hline
\end{tabular}




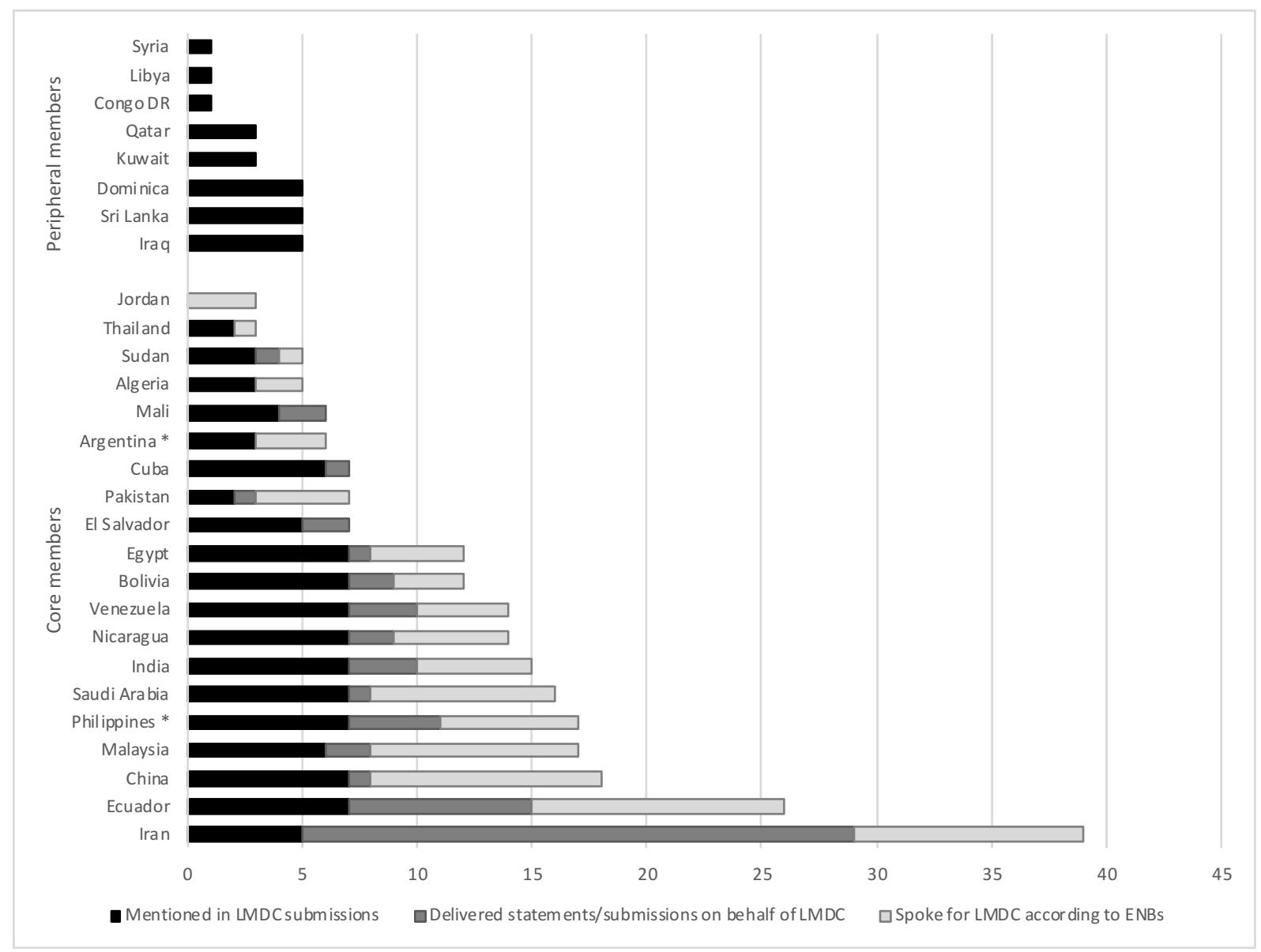

Figure 1: LMDC membership by number of explicit mentions in negotiation documents and summaries.

Note: The Philippines and Argentina left LMDC in December 2014 and December 2015, respectively. 

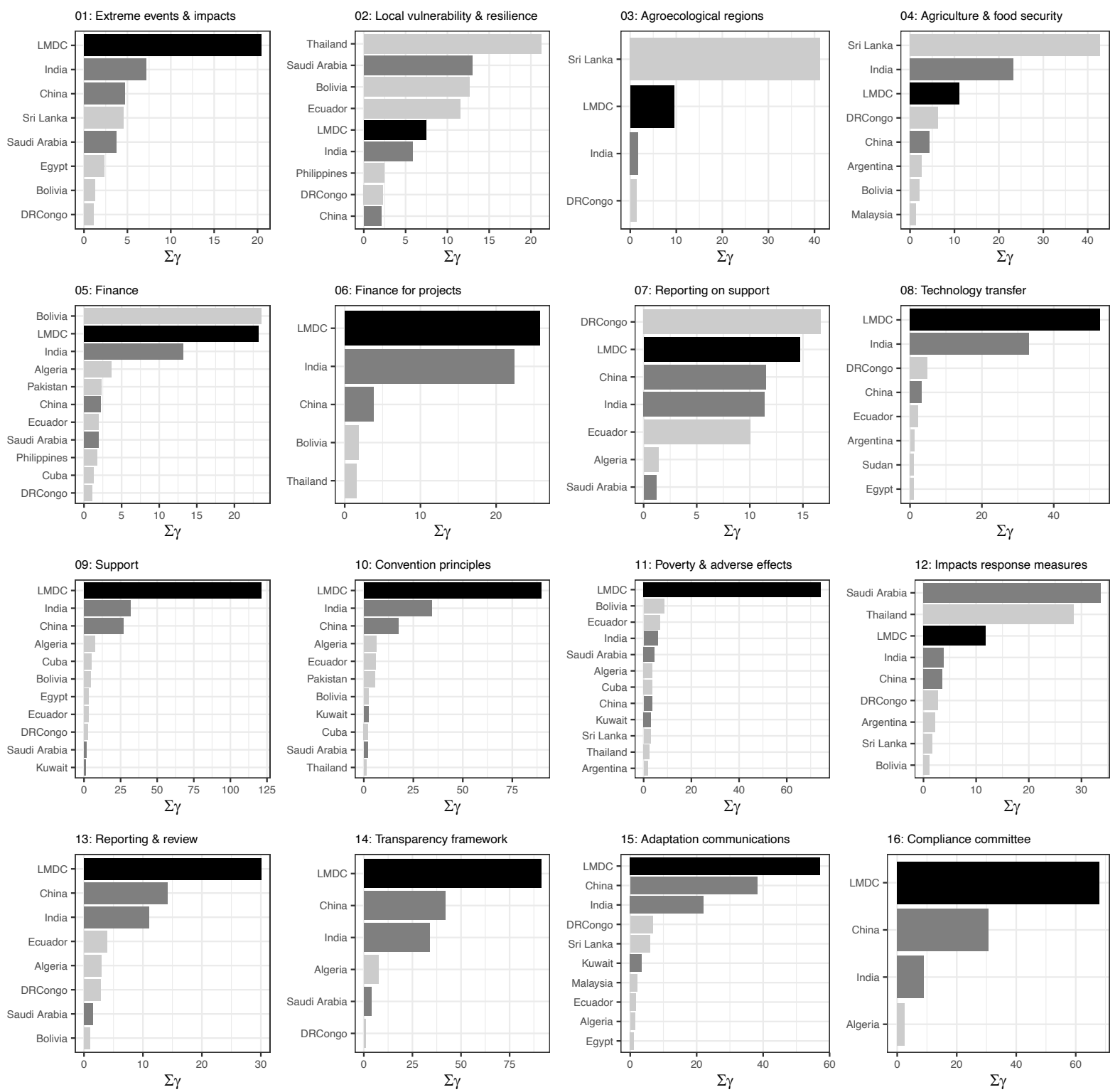

Figure 2: LMDC, members and subgroups with highest prevalence for each topic.

Note: Weaker members are in light grey, stronger members and subgroups in dark grey, the coalition itself in black. 

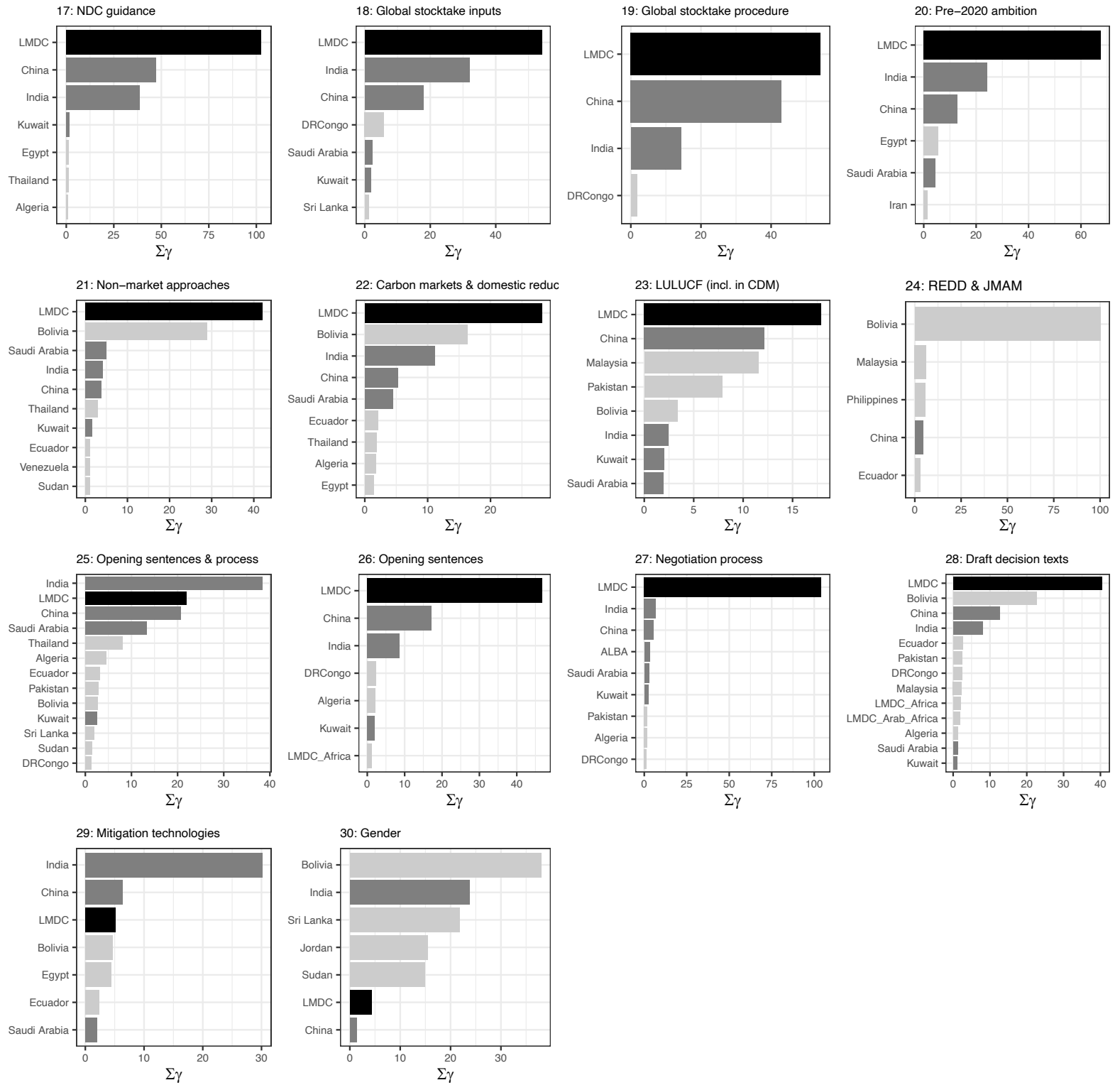

Figure 2 (continued). 
Supplementary File for:

National interests and coalition positions on climate change: A text-based analysis

\author{
Paula Castro (paula.castro@zhaw.ch)
}

Center for Energy and Environment,

Zurich University of Applied Sciences

\title{
Contents
}

Appendix A: Data

- Table A1: Details of text corpus

- Figure A1: LMDC and member submissions over time

- Figure A2: LMDC and member submissions by country

- Figure A3: LMDC and member submissions by (simplified) UNFCCC agenda item

Appendix B: The Structural Topic Model (STM)

- Pre-processing of the corpus

- Topics identified

- Figure B1: Topics identified in the UNFCCC submissions corpus, ordered by prevalence

- Figure B2: Average topic prevalence over time

- Figure B3: STM topics versus UNFCCC agenda items 


\section{Appendix A: Data}

\section{Table A1: Details of text corpus}

\begin{tabular}{lcc}
\hline \multicolumn{1}{c}{ Negotiation body } & $\begin{array}{c}\text { Time period with } \\
\text { submissions }\end{array}$ & $\begin{array}{c}\text { Submissions by } \\
\text { LMDC }(*)\end{array}$ \\
\hline Ad-Hoc Working Group on the Durban Platform & $2013-2015$ & 51 \\
Ad-Hoc Working Group on the Paris Agreement & $2016-2018$ & 49 \\
Conference of the Parties & $2013-2018$ & 15 \\
Subsidiary Bodies & $2013-2018$ & 16 \\
Subsidiary Body for Implementation & $2013-2018$ & 24 \\
Subsidiary Body for Scientific and Technological Advice & $2013-2018$ & 61 \\
Unknown & $2013-2017$ & 6 \\
Total & $2007-2018$ & 222 \\
Total number of words in the corpus & $2007-2018$ & 373546 \\
\hline (*): Including submissions by individual members, subgroups of members, or by the whole coalition together with \\
other groups.
\end{tabular}


Figure A1: LMDC and member submissions over time

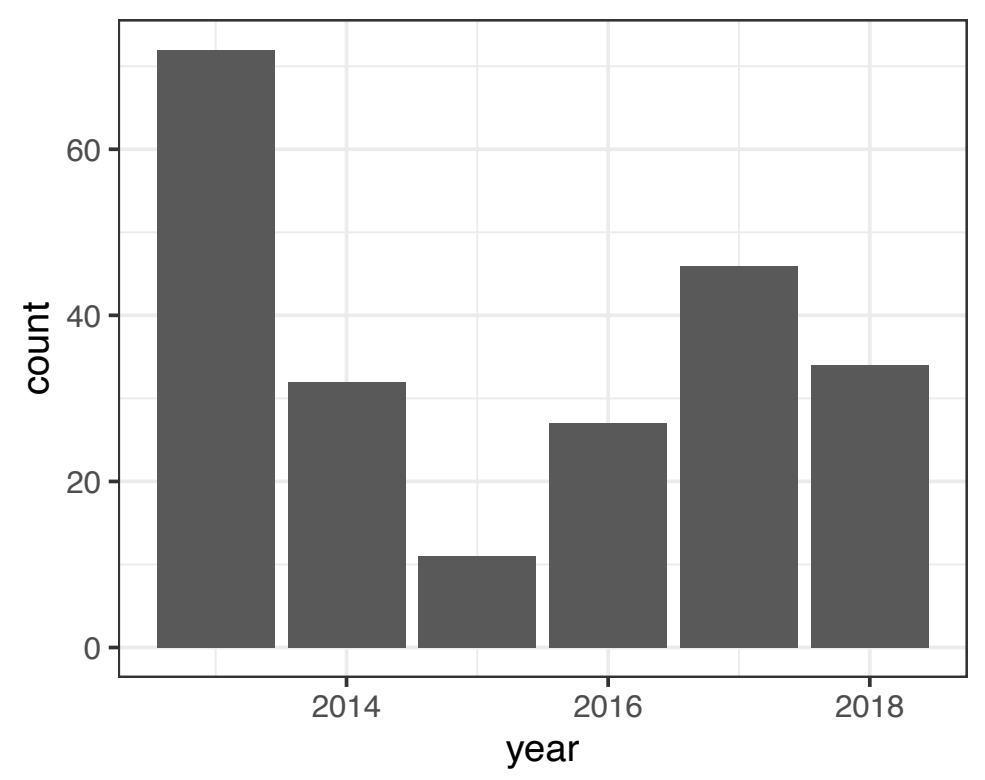

Figure A2: LMDC and member submissions by country

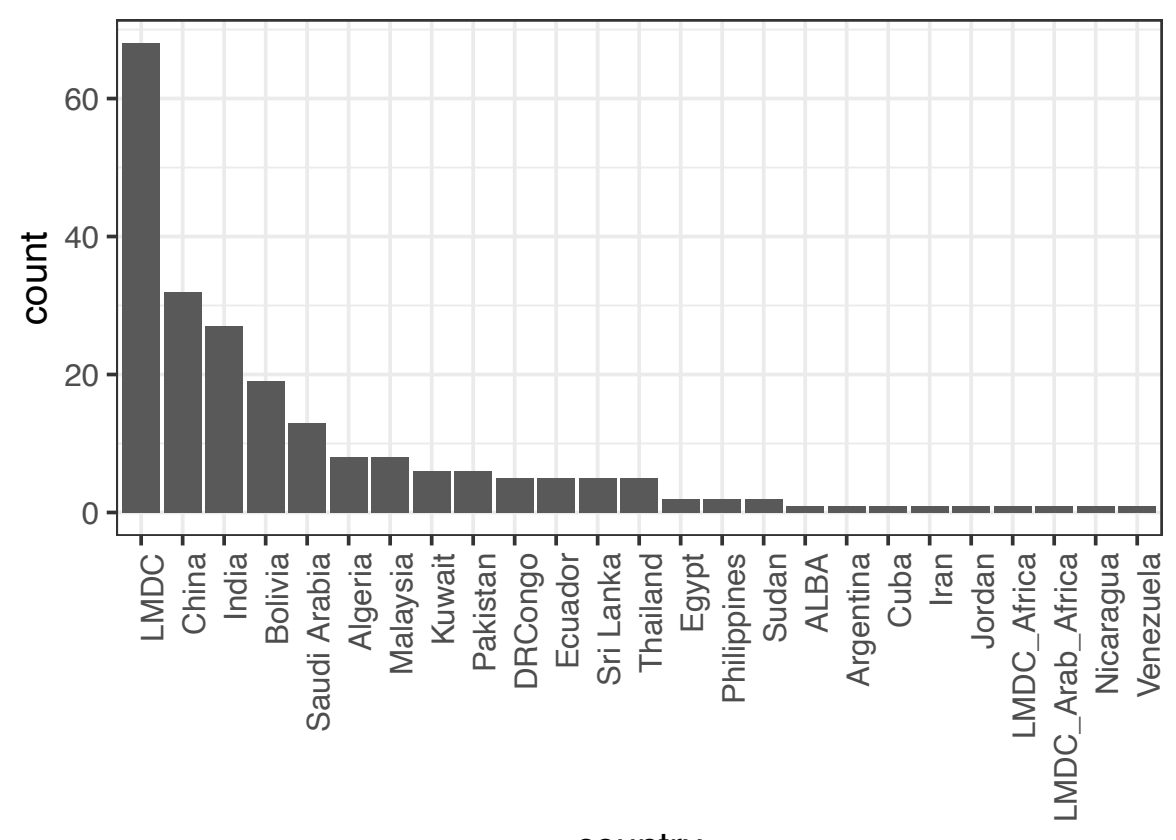

country 
Figure A3: LMDC and member submissions by (simplified) UNFCCC agenda item(*)

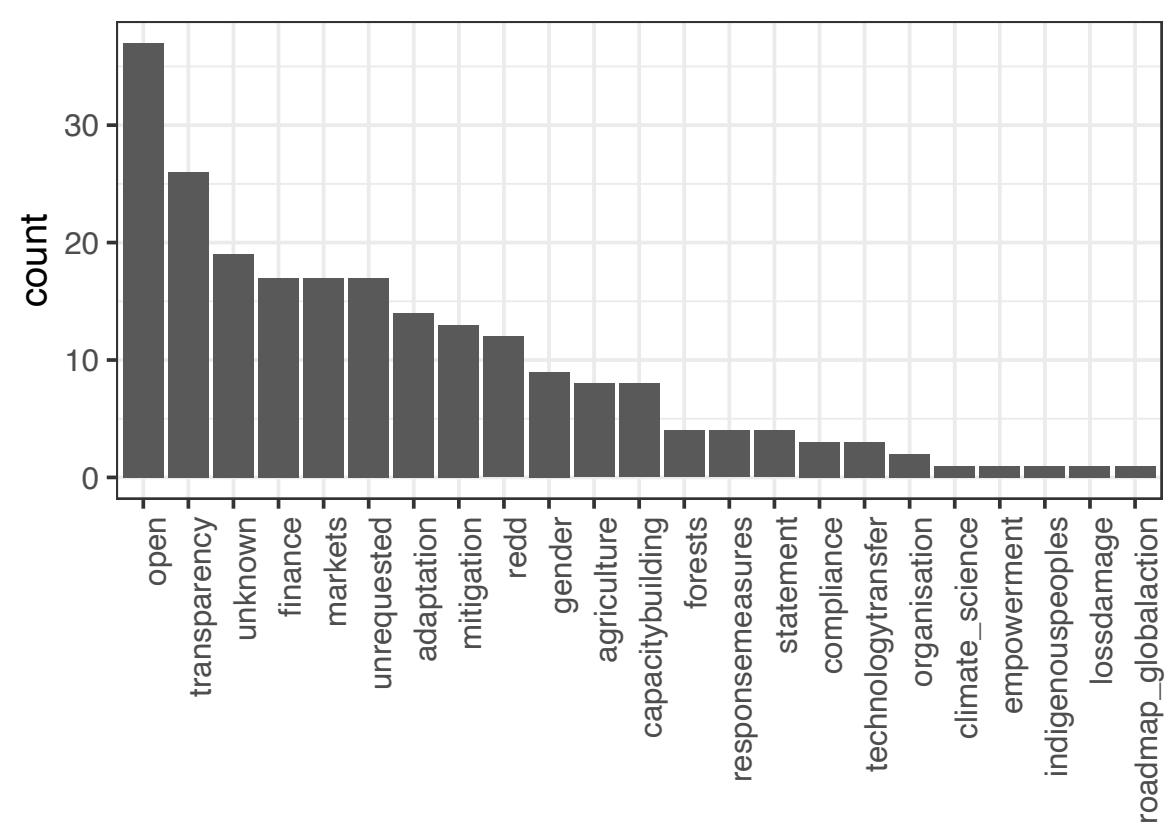

agenda item

$(*)$ : The agenda items were hand-coded on the basis of the respective calls for submissions, and aggregated into broader issue areas. For example, the agenda item "markets" in the graph covers submissions on market-based mechanisms, non-market mechanisms, on forests under the CDM, and on Articles 6.2, 6.4 and 6.8 under the Paris Agreement.

The data and code for the empirical part of this article are available in Paula Castro's Harvard Dataverse at: https://dataverse.harvard.edu/dataverse/paulacastro. 


\section{Appendix B: The Structural Topic Model (STM)}

\section{Pre-processing of the corpus}

Before running the STM, the corpus of submissions was cleaned and pre-processed. The cleaning implied first removing all non-English sections (e.g., some submissions are sent in English and French, or English and Spanish versions), and removing lists of references or bibliography. I also removed all standard stopwords (words used very frequently that carry little meaning, such as articles ("the", "a") or prepositions (“in")), numbers, symbols, URLs and punctuation, and the name of the coalition and its member countries. As an additional pre-processing step I built key-phrases by putting together the forty compounded expressions most frequently found across all texts, which may carry a particular meaning of their own and are thus better analysed as single expressions.

One challenge in analysing these submissions is that they often address several issues on the agenda at the same time - many calls for submissions are relatively broad. In order to allow a better classification of the topics - in terms of manually labelling them on the basis of the most frequent and most exclusive words, and of the most typical sections of text representing each topic, I thus needed shorter and more specific text sections. For this reason, the texts were subdivided into equal 50-word long sections (or 'chunks'). The STM was run on the basis of these small text chunks. I also tried using longer (100-word) text chunks, and even longer text sections (subdivided on the basis of subheadings within each submission) but the identification of single topics was more difficult in these cases. Shorter text chunks, in contrast, risk containing too few words for the model to be able to identify specific topics from them.

The use of equal-length word sections offers the additional advantage of making it easier to calculate measures of topic prevalence at the level of the full submissions, UNFCCC agenda items or individual countries. 


\section{Topics identified}

The STM model does an excellent job of discriminating the issue areas or agenda items being discussed in the climate negotiations. The resulting topics also offer information about more specific priorities of LMDC and its members within agenda items, given that often several topics relate to a specific issue area, reflecting specific aspects prioritized by different countries. In addition, they convey some of the more general negotiation positions heralded by LMDC and its members, and in some cases reflect typical negotiation language.

A first group of topics addresses issues related to vulnerability and impacts of climate change (topics 1 and 2), in particular also in relation to agriculture and food security (topics 3 and 4). A second group relates to finance and support, covering issues related to the financial mechanism and the finance target (topic 5), to funding needs for specific projects (topic 6), to how developed countries should report the support provided (topic 7), to technology transfer (topic 8), as well as broader demands for sufficient support to cover developing countries' adaptation and mitigation actions (topic 9). Several cross-cutting issues that developing countries (and LMDC members in particular) have cared about throughout the history of the climate regime are also identified, including the Convention principles of Common but Differentiated Responsibilities and Respective Capabilities (CBDR-RC) and of equity (topic 10), the importance of poverty eradication, sustainable development and the avoidance of adverse effects from climate change (topic 11), and the impacts of response measures (topic 12). A fourth set of topics addresses issues related to reporting, review of progress and compliance, both under the Convention (topic 13), and under the Paris Agreement (topics 14-16). Discussions on NDC guidance and on the global stocktake under the Paris Agreement, as well as on pre-2020 ambition as discussed under the ADP are identified in topics 17 to 20 . A further set of topics refers to market and non-market approaches, including REDD (reducing emissions from deforestation and forest degradation), a Joint Mitigation and Adaptation Mechanism (JMAM) proposed by Bolivia, and discussions on accounting for land-use and land-use change (LULUCF), including under the Kyoto Protocol's Clean Development Mechanism (CDM) (topics 21-24). A set of topics captures general language typical of the opening sentences of submissions, language on the organization of the negotiation process, and language on drafting decision texts (topics 25-28). The final two topics refer to examples of 
mitigation technologies and policies being adopted by individual countries (topic 29), and to gender-specific aspects related to climate change and policies (topic 30).

Figure B1 below displays all topics in order of decreasing prevalence, and shows the most frequent and exclusive words that identify each of them. Among the most prevalent topics are some of the issues at the core of the post-Paris negotiations, such as guidance for producing the NDCs, the transparency framework and the adaptation communications. At the same time, the fact that the provision of financial, capacity building and technological support is the most prevalent topic overall does not surprise, given that receiving adequate and sufficient support to address mitigation and adaptation is a key demand of developing countries in general, while the LMDC frequently highlight developed countries' obligation to provide such support. Similarly, the topic model is accurate in identifying the principles of the Convention as one of the topics that most often appears in submissions by LMDC and its members, which is in line with the positions and narratives most strongly defended by the group (Blaxekjær et al., 2016).

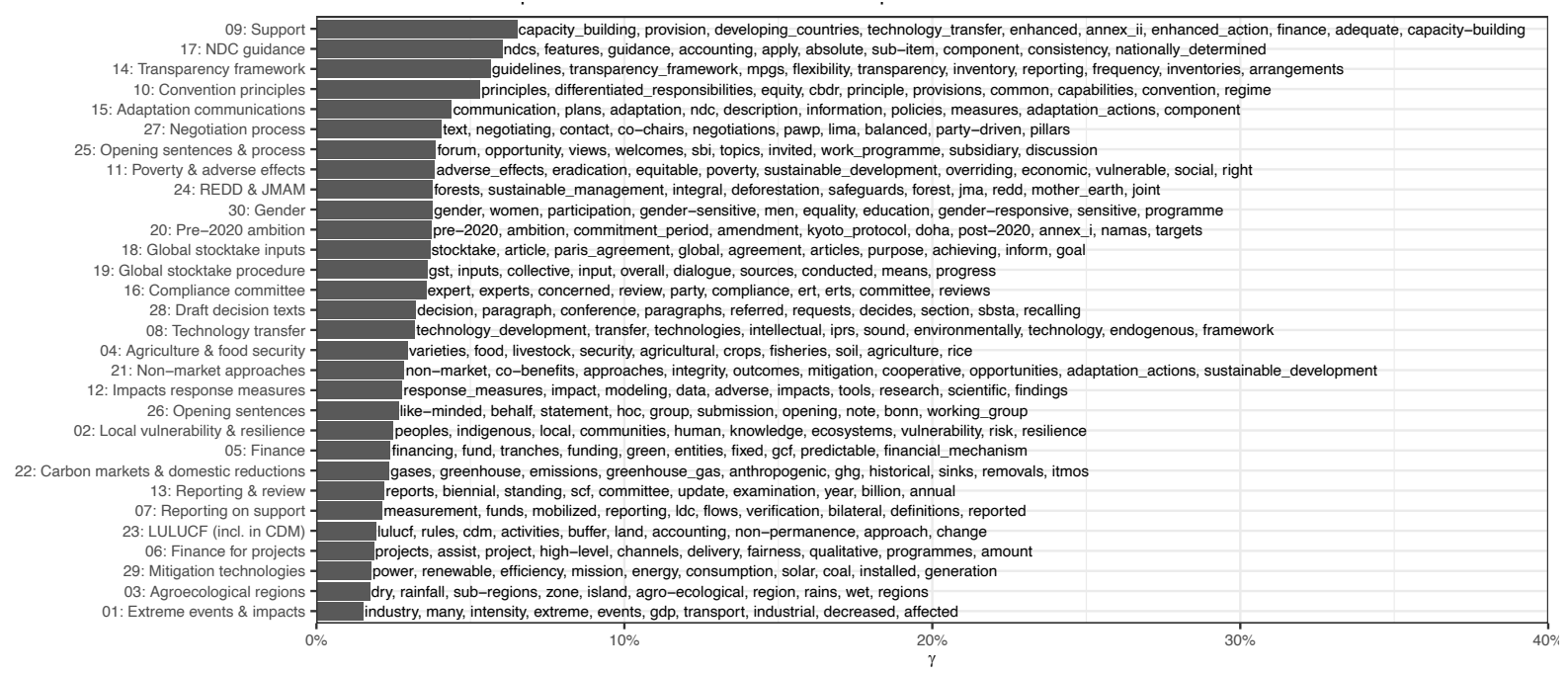

Figure B1: Topics identified in the UNFCCC submissions corpus, ordered by prevalence. For each topic, the ten words with the highest frequency and exclusivity (frex) ranking are shown. 

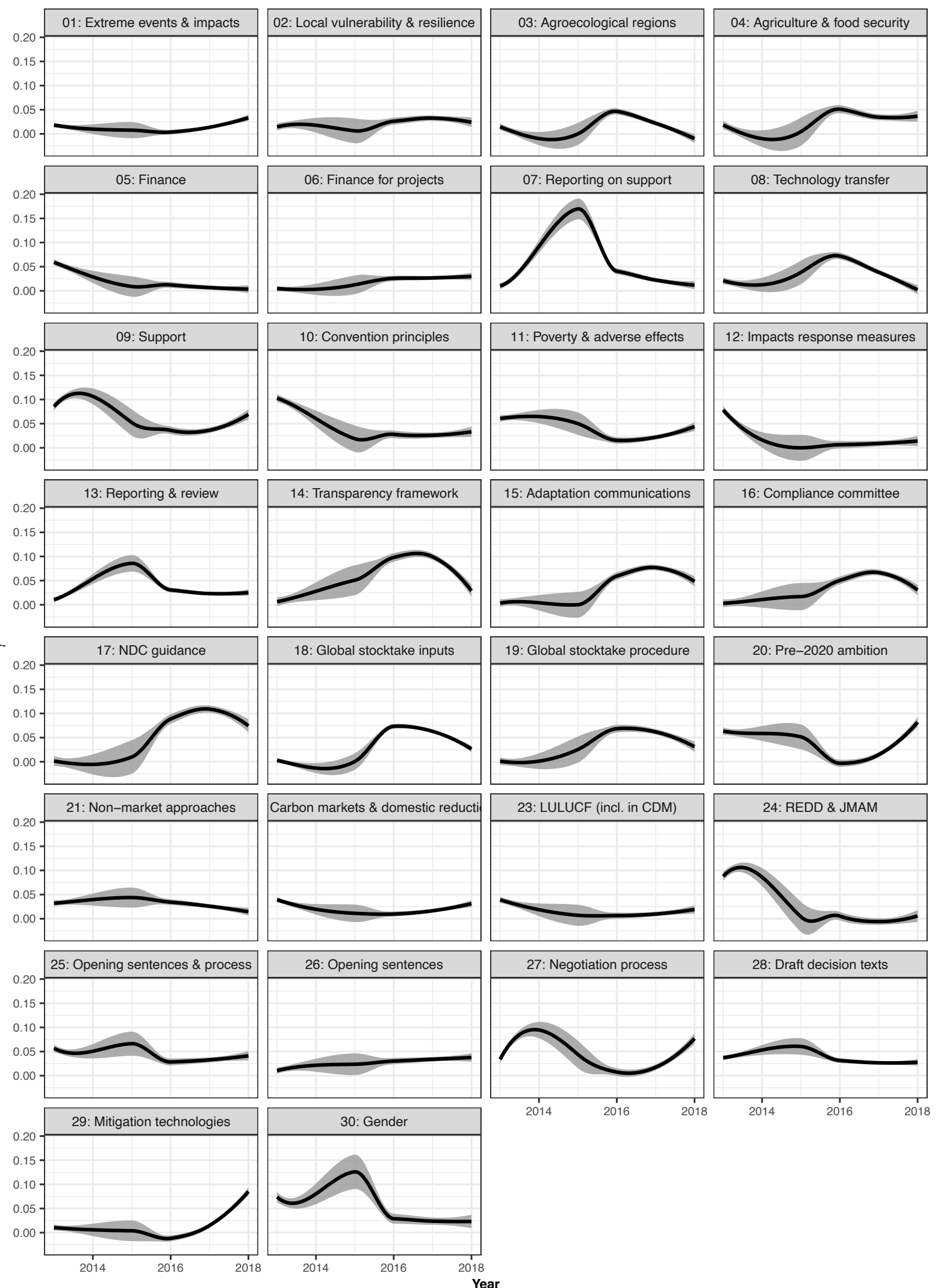

Figure B2: Average topic prevalence over time 
Figure B2 above displays how the prevalence of each topic evolves over time. This evolution matches quite well the actual development of the negotiations over time, which is a further indication that the model performs well. For example, topics related to the implementation of the Paris Agreement (topics 14 to 19 on the transparency framework, adaptation communications, compliance committee, NDC guidelines and global stocktake) have the highest prevalence in the years 2016 to 2018, reflecting the main post-Paris agenda. In contrast, broader - more political - LMDC priorities, such as support, the Convention principles, developing countries' priorities in terms of eradicating poverty and achieving sustainable development, and the impacts of response measures, tend to have a higher prevalence in the period up to 2015, reflecting the broader political themes - such as differentiation - that predated the negotiations towards the Paris Agreement.

Figure B3 below, finally, presents how the STM topics relate to the actual agenda issues in the UNFCCC agenda. The agenda items were hand-coded on the basis of the respective calls for submissions issued by the UNFCCC. They were then aggregated into broader issue areas. For example, the agenda issue coded as 'markets' in the graph covers calls for submissions on market-based mechanisms, non-market mechanisms, on the treatment of land-use, land-use change and forests (LULUCF) under the Clean Development Mechanism (CDM), and on Articles 6.2, 6.4 and 6.8 under the Paris Agreement. The graph shows that some agenda issues are quite specific in their scope. For instance, the agenda issue coded as 'mitigation' is mostly covered by the topic 'NDC guidance'. Other agenda issues are very broad. A clear example are those coded as 'open' in the graph, which mainly reflects general calls for views on all aspects of the ADP process, or on workstreams 1 and/or 2 under the ADP. These open calls for submissions are covered by a large range of the topics identified in the STM. 


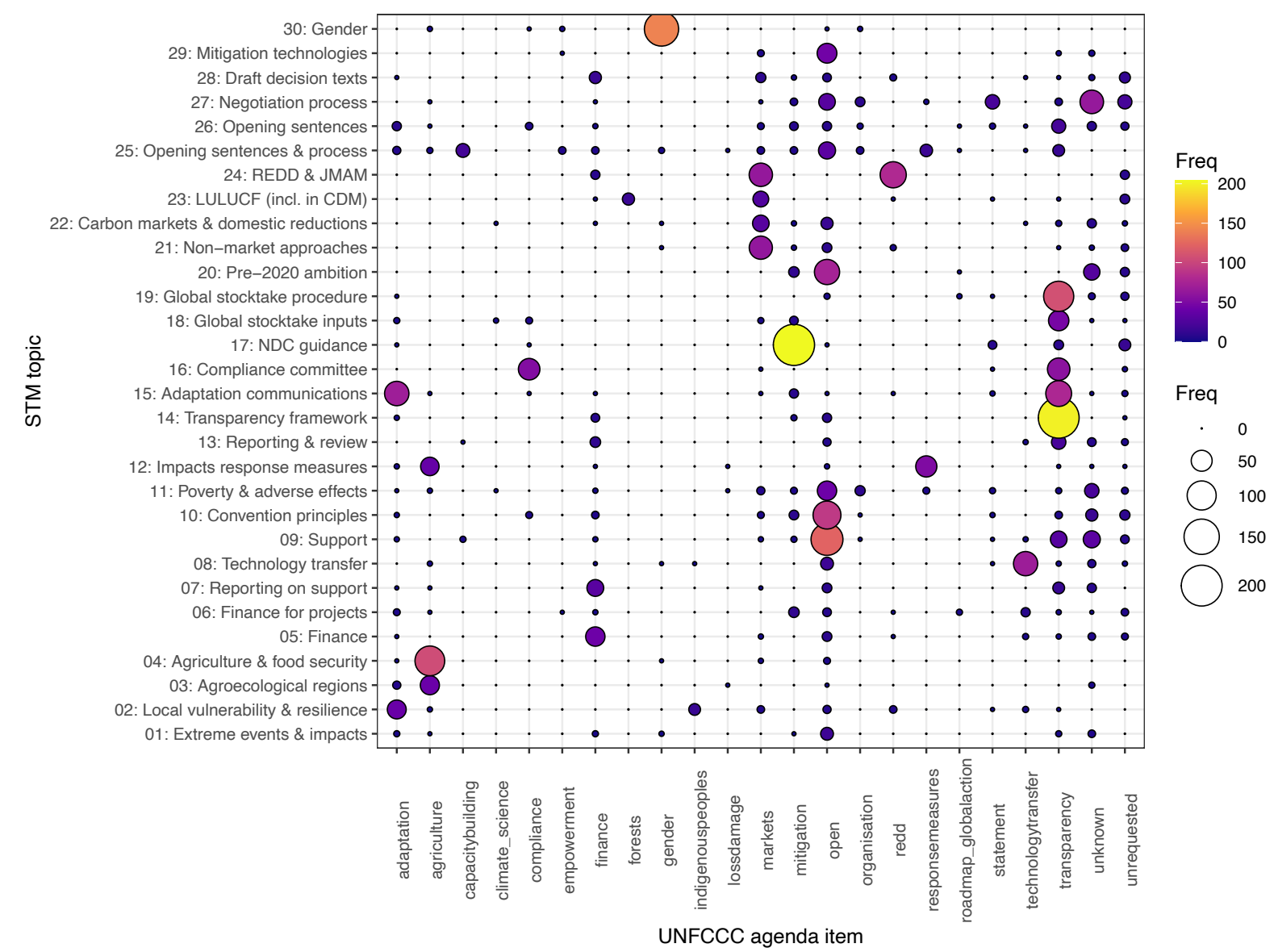

Figure B3: STM topics versus UNFCCC agenda items 